\title{
CX. The measurement of light
}

\author{
John W.T. Walsh M.A. M.Sc.
}

To cite this article: John W.T. Walsh M.A. M.Sc. (1922) CX. The measurement of light, Philosophical Magazine Series 6, 44:264, 1165-1168, DOI: 10.1080/14786441008634084

To link to this article: http://dx.doi.org/10.1080/14786441008634084

$$
\text { 册 Published online: } 08 \text { Apr } 2009 .
$$

Submit your article to this journal

LII Article views: 4

Q View related articles ¿ 


\section{$\left[\begin{array}{ll}1165 & ]\end{array}\right.$}

CX. The Measurement of Iirllt. By JoHN W. T. WALsH, MI.A., M.St., (Departiment of Photometry and Illumination, Vational Physical Laboratory) *

$I^{1}$ $\mathrm{N}$ an article published under the above title in a $r$ cent. number of this Magaxino $\dagger$, Dr. Norman Campoell and Mr. B. P. Dudding have eriticised the logical foundation of commonly accepted systems of definitions and in particular the system adopted for the definitions of the principal photometric magnitudes. Their conclusions may, perhaps, be briefly summarized as follows :-

(1) The fundamental photometric magnitude is illumination $(\mathrm{I})$.

(2) Illumination is characteristic, not of the surface illuminated, but of the cireumstances in which that surface is placed.

(3) It can be shown experimentally that illumination is subject to the laws of addition if the conditions under which the Purkinje effect operutes be eicchuded.

(4) On the ahove bases the inverse square law can he demonstrated by suitable experiment, and, this done, the cosine law of illumination can be demonstrated.

(5) With the proven fact of the inverse square law the definition of luminous intensity [candle-power] in a given direction follows at once from that of illumination $\left(\Phi=\mathrm{I} r^{2}\right)$

(6) By integrating the intensity in all directions a new quantity $\mathrm{F}=\int \Phi d \omega$ is obtained ( $\omega$ is solid angle). $\mathrm{F}$ is characteristic of the source alone, and is termed the flux of light from the source.

(7) Brightness, $\mathrm{B}$, is defined as the intensity of unit projected area $(\Phi / \mathrm{S} \cos \alpha) f(\alpha)$, or normal brightness is $\Phi / S$ where $S$ is area.

'T'hus the system proposed by the authors gives the chief photometric definitions in the order (1) illumination, (2) luminous intensity, (3) luminous flux, and (4) brightness. This order differs from that adopted by both the American and the British National Illumination Committees in their systems of definitions proposed before the Iuternational Commission on Illumination last year $\ddagger$. It is, therefore, desirable to examine the reason for the difference with the object of arriving, if possible, at the most natural order.

* Communicated by the Author.

+ Phil. Mag. Sept. 1922, p. 577 .

f Commission Internationale de l'Eclairage, 5me Session, Paris 1921. Rapports (in the press). 
In the American definitions * the first photometric magnitude defined is luminous flux, followed by luminousintensity, illumination and brightness.

In the British definitions $†$ the order is luminons intensity, luminous flux, illumination and brightness.

These two systems follow the respective customs of the two countries as to the rating of illuminants. In Great Britain a luminous source is rated in candles, while in Ameriea the lumen is amost universally adopted.

The existing official definitions, then, adopt as their starting point the magnitude in which the unit is realized in practice, for hoth luminous flux aud huminous intensity are characteristic of the source alone and are independent of any other material body.

It is true that both luminous flux aud luminous intensity are impossible of measurement per se, and it is not until the source illuminates some surface that either the flux or the intensity can be measured. It "ould thus appear that, in deciding on our first defined magnitude, we have to choose between $(a)$ the maginitude most intimately connected with the material standard by which our unit is maintained, and (b) the magnitude which is directly measurable.

The authors of the paper referred to above apparently aim at the second choice, but it is difficult to understand why, after the irrefutable statement that "light measurements are based on judgments of equality of brightness of photometric surfaces," they go on without explanation to say that " the fundamental photometric mannitude is illumination."

In fact illumination appears to be the most abstruse of all the photometric magnitudes and the one of which it is most difficult to form a mental concept. It is not easy, for example, to decide whether illumination exists in the absence of a surface.

Physical photometry being disregurded, it is clear that the fundamental photometric magnitude from the point of view of measuremint is "brightness." Illumination follows as that which causes surfaces to have brightness. Luminous intensity and luminous flux then follow as before.

In this connexion the proviso made by Dr. Campbell and Mr. Dudding as to the avoidance of the Purlinje effect is most interesting. On page 5 82 they say "But the second law of addition is not true in all circumstances; it is not true, for "xample, when the Purkinje effect is apparent. For, if $R_{1}$ and $h_{2}$ are red sources, $B_{1}$ and $B_{2}$ blue sources, and if the illumination from $R_{1}$ is equal to that from $B_{1}$, and

* Illum. Eng. Soc. N.Y. Trans. xiii. (1918).

† Illuminating Engineer, London, xv. (1922). 
that from $R_{2}$ to that from $B_{2}$, the illomination from $R_{1}$ and $\mathrm{R}_{2}$ will not be always equal to that from $B_{1}$ and $l_{2}$."

'This' statement is most surprising, especially if taken in connexion with a previous statement that illumination is "characteristic, not of the surface illuminited, bat of the circumstances in which it is placed." These two statements are not easily reconciled, for it is easily possible to imagine two pairs of photometric surfaces, one pair of high reflexion ratio and one of low reflexion ratio, so that in the former case the addition law of illumination may he found to hold, while in the latter case with the same illuminations it does not. Surely if the statement first quoted be true, the second is refuted.

It seems, on the whole, more consistent to regard illumination as independent both of the nature of the surface illuminated and of such essentially ocular phenomena as the Purkinje effect. The latter can, and must, bo reckoned with when considering brightness, and the statement first quoted ahove is quite intelligible if read as referring to the addition of brightness, and if the words "brightuess due to" be substituted for "illumination from."

It seems, then, that we have to choose between a system of definitions depending on (a) brightness, and (b) luminous intensity or luminous flux, as the fundamental magnitude.

It seems to the writer at least a doubtful contention that it is more logical to start with the magnitude actually perceived and measured and to work back to the magnitude in which the unit is maintained. In either case the physical laws connecting the varions magnitudes in the chain have to be known and, in fact, they must be described, at any rate by implication, in the definitions of the dependent magnitides.

The gain, if any, in logical security seems to be more than counierbalanced by a very marked loss of "concreteness" -never a pronounced characteristic of formal definitions. The mind natumily linds it most easy to form a picture of the magnitude in which the unit is maintained, that being a phenomenon having the closest association with a concrete object. In the case of photometry it would seem that the luminous intensity, or candle-power, of a source in a given direction is far more reallily understood as a basis of definitions than is the brightness of a surface viewed in a given direction. For the natural physical order is $(a)$ emission of luminous flux by a source owing to its luminous intensity, $(b)$ incidence of this flux at a surface, $(c)$ brightness of this surface due to the illumination and the power of the surface to reflect light. This is, then, the order in which the mind expects the magnitudes to be defined, and it appears to the writer the preferable order for that reason. 
The function of a system of definitions is, in the writer's opinion, so to describe a number of different quantities and their relations to one another that a previous understanding of any one of these quantities (regarded as the fundamental), together with the definitions, enables all the remaining quantities to be understood also. If this be granted, the fundamental yuantity should be that most generally understood. The sequence of the remaining quantities is then a matter of convenience.

In conclusion, it may not be out of place to point out that Dr. Camphell and Mr. Dudding appear not to have understool the "lambert" "is a unit of hrightnoss. It is unfortunate that they were apparently only aware of the brief statement in the Report of the Standards Committee of the Optical Society of America* that "a lambert is the brightness of a surface emitting one lumen per square centimetre of projected area in the direction considered." They naturally remark that "To speak of a lumen emitted in a dirertion is to talk nonsense."

Although, of course, this description of the lambert is quite unsound, it is unfortunate, to say the least, that the authors did not refer to the official definition of the lambert (by no means a new unit). They would then have realized that their difficulty arose, not from a miscalculation on the part of the American Committee as they seem to infer, but from an inaccuracy in the wording. "A lambert is the brightness of a perfectly diffusing surface (i.t. one obeying the cosine law of emission) emitting or refecting one lumen per square centimetre" $\uparrow$.

\section{Summary.}

(1) The fundamental photometric magnitude from the point of view of visual measurement is brightness and not illumination.

(2) The photometric unit is one of luminous intensity (candle-power) or luminous flux.

(3) Of the two possible systems of definitions based on these respective magnitudes, that based on the magnitudes in which the unit is mintained seems preferable because it follows the natural order of mental conception.

(4) The relation between the flux unit of brightness (the lambert) and the intensity unit (the candle per square centimetre) is pointed out.

* Opt. Soc. Am. J. ir. p. $230(1920)$.

$\dagger$ Repont of Standards Conmittee of the Illum. Eng. Soc. N. Y. 'irans. xiij. (1918). 